\title{
Management of business records in Tanzania: an exploratory case study of selected companies
}

\section{B. Chachage}

Information Studies Programme

University of KwaZulu-Natal

Pietermaritzburg, South Africa

Bukaza@avu.org or Mwani@msm.nl

\section{P. Ngulube}

Information Studies Programme

University of KwaZulu-Natal

Pietermaritzburg, South Africa

ngulubep@ukzn.ac.za

\section{Contents}

1. Introduction

2. Overview of business records management in Tanzania

3. Theoretical foundations of the study

3.1 Records life-cycle

3.2 Records continuum

3.3 Hybrid records life-cycle theory

3.4 Linking the theoretical framework to the research problem

4. Methodology: a short research story

5. Challenges to managing business records in Tanzania: presenting the findings

5.1 Policies for the management of records and management support for the records programme

5.2 Managing electronic records

5.3 Compliance and standards

5.4 Staffing and professionalism

5.5 Vital records protection programmes

5.6 Disposition and retention of records

5.7 Disaster management and control

5.8 Managing access to business records

6. Concluding remarks

7. References 
Key words: Business records, records management, records life-cycle, continuum and hybrid models

\section{Introduction}

Every business is involved in the production of records in its processes. Therefore records management is one of the by products of business processes. Together with the commonly known administrative, historical and archival reasons, businesses keep records to fulfil legal requirements for their operations and protect the rights of stakeholders.

For instance, many companies in east and southern Africa have to keep records for a certain period of time in compliance with the requirements of tax, company, and customs and excise regulations. The maintenance of proper records may help companies to avoid paying unnecessary fines and lawsuit settlements costs. Furthermore, records would provide evidence of transparency and accountability of private business to stakeholders. The passing of the 'freedom of information' legislation in some countries underscores the need for business records to be managed so that they will be available when citizens request to have access to them in terms of the law.

Scholars have been arguing for comprehensive and coordinated information policies to cater for information generated by public and private institutions in various countries, and Tanzania in not an exception. In the case of Tanzania, scholars such as Sekimang'a (1992) and Mukangara (2000) indicate the need for an overall coordinated policy to direct information activities in the country. As part of the response to proposals of various stakeholders, the government of Tanzania promulgated the Records Management Act (United Republic of Tanzania 2002). However, the Act does not adequately address the management of private business records. In additional to that, many records management studies conducted in Tanzania only dealt with public records (Kalumuna 2000; Kitalu 2001; Ndibalema 2001; Nyirenda 1993). Neglecting the management of business records is not peculiar to Tanzania; it is also prevalent in countries in southern and eastern Africa (Eastwood 2006; ESARBICA 2005). Therefore the research dealing with corporate records management in the Iringa region of Tanzania is likely to raise awareness on the need to manage business records and open up debate on the merits and demerits of their management and preservation.

Although Eastwood (2006) points out that the management of records of private organizations has not been fully incorporated into archival theory and practice worldwide, scholars in the developed world are gradually recognizing the importance of managing business records. For instance, the Records Management Journal volume 13 issue 3 of 2003 was devoted to managing business records from an international perspective, although there were no contributions, particularly from Africa.

\section{Overview of business records management in Tanzania}

The historical background of business records management in Tanzania can be traced to before AD 1000 in the coastal areas of Tanzania. Trade in the coastal areas of Tanzania had traceable business contacts with Egypt, India, China, Assyria, Phoenicia, Arabia, Greece and Rome (Mwango 2000). Some records were created during their trading encounters. When missionaries, hunters and explorers came, after the fifteenth century, they, 'recorded whatever they saw and experienced in respect to social-cultural life of indigenous people as 
well as their economic activities' (Mwango 2000:11).

Although the history of business records keeping in Tanzania is a long one, it was the Germans and Britons who formalized procedures for records management during the colonial period. By 1891 some formal records keeping systems were functioning properly with formal subject filing systems in the then Tanganyika (Mwango 2000:13). However, in the current government information infrastructure the management of private business records is not properly addressed. The Records and Archives Management Act (United Republic of Tanzania 2002) pays little attention to business records at a time when the majority of government enterprises are being privatized. In section 26(1), for instance, the Act indicates an interest in only acquiring private records of national importance and public interest. The question is: How would the National Archives identify private records of national interest if there is no law regarding their management and a clear mandate for National Archives to identify and manage them?

A content analysis of national archival legislation in east and southern Africa showed that the framework to deal with records of private organizations was inadequate. It is in this context that Abbot (2001:64-65) complains about the absence of legislation for implementing formal records management programmes in private institutions in South Africa, for instance. However, in South Africa, the Promotion of Access to Information Act, No 2 of 2000, which requires private institutions to present a manual with the narration of records holdings, raises some hope for formal private records management programmes in South Africa.

\section{Theoretical framework of the study}

The records life-cycle and records continuum models are the dominant theories in the archival and records management field. However, the study reported in this article was built on the 'modified' records life-cycle theory that blended the records life-cycle concept and continuum model. In addition to the two dominant records management theories, there is the less popular records entity life history theory (Shepherd and Yeo 2003:8). The limited information on this theory hinders its further discussion in this article. The discussion of the life-cycle concept and records continuum follows.

\subsection{Records life-cycle}

Records life-cycle is the core concept in the field of records management. According to Akussah (1996:101), 'It is ... universally acceptable among archivist and records management professionals that the cycle concept is the most integrated and comprehensive approach to records management'. Probably, that partly explains why it is popularly used as a framework for managing public sector records in eastern and southern Africa (Ngulube and Tafor 2006).

Historically, Theodore Schellenberg invented the records life-cycle concept while working in the National Archives of the USA in the 1930s (Shepherd and Yeo 2003:5). According to the life-cycle records management framework, records pass through various conceptual stages during their life. Different scholars present these stages differently. For instance, Charman (1984), Hardcastle (1989), Hare and McLeod (1997), and Penn, Pennix and Coulson (1994) share the view that records pass through an active or current phase to a semi-active or semicurrent state and then to a non-active or non-current stage. The evolving nature of the records life-cycle concept and the advent of information technologies made scholars visualize more stages in the life-cycle concept. For instance, Goodman (1994) lists ten stages of the records life-cycle concept, namely: 
- Design and creation of records

- Identification

- Authorization

- Verification

- Validation and auditing

- Circulation

- Access

- Loan and use

- Backup procedures and disaster recovery plans

- Retention schedules and destruction.

From these differences in the interpretations of the life-cycle model's stages, it is evident that the records life-cycle theory is a conceptual visualization and not a compartmentalization of the records' life into distinct spaces and times. Contrary to the widely held view of the proponents of the continuum model, the records life-cycle framework neither fixes stages in the management of records nor assigns any particular professional group to their management. The records life-cycle concept only provides a structure for effective and efficient records management (Penn, Pennix and Coulson 1994:12).

Furthermore, in light of the systems thinking theory where everything is connected to everything else, one may argue that the stages of the records life-cycle are subsystems that constitute the model as opposed to compartments perceived by those opposed to the model. Senge (1990) points out that one of the fundamentals of systemic thinking is to view the system as a whole and realizing that the whole is greater than the sum of its parts. In that regard, the focus should be on the system - records life-cycle model - instead of the individual conceptual stages.

\subsection{Records continuum}

The proliferation of information and communication technologies (ICTs) and the perceived shortcomings of the records life-cycle motivated scholars to suggest a records continuum model in the field of records management (An 2001; Flynn 2001; Upward 2000; 2005). Theorists such as Frank Upward, Sue McKemmish, Barbara Reed and Don Schauder adopted the records continuum model as an alternative to the records life-cycle to cater for electronic records (Chachage 2005; Flynn 2001). Furthermore, some scholars favoured the records continuum theory as opposed to the life-cycle model because they argued that it combined records management and archival activities in the management of recorded information. For instance McKemmish, Reed and Piggott (2005:193) assert that:

'Our traditional theory and practice has been derived from a physical world where archiving processes tended to apply only in custodial archival keepingplaces. Australian archival practice in the "series" system broke that physical nexus, and subsequent evolution of practice within the records continuum framework has extended the boundaries of archival systems...'

Historically, Ian Maclean is credited for having started the records continuum debate (Upward 2000:118). As national archivist of Australia, he held the notion that the work of archivists and records managers were interrelated and that there was continuity between records management and archives. Accordingly, the concern to manage recorded information connected the two professions. The Canadian archivist Jay Atherton proposed the term 'continuum' to describe Maclean's concept. Atherton was the first person to show the difference between the records continuum and records life-cycle (Upward 2000). The Standards Association of Australia (1996) defines records continuum as:

'a consistent and coherent regime of management processes from the time of the 
creation of records (and before creation, in the design of records keeping systems), through to the preservation and use of records as archives'.

Thus in the continuum model the records management process is regarded as a continuous activity that focuses on the operations that produce records (Bantin 2002:69).

Specifically, the records continuum model was developed in the 1980s and 1990s (Shepherd and Yeo 2003:9). Based on the continuum model, archivists and records managers need to be involved together with information systems designers in the creation of records keeping systems. Flynn (2001) refers to this design stage as the pre-natal phase. Records managers and archivists appraise records and decide on what records would support the functions of an organization during the records keeping system design. Scholars such as Kennedy and Schauder (1999), Myburgh (2005) and Shepherd and Yeo (2003) emphasize the need for collaboration between records professionals and information systems experts during systems design.

Put differently, the main emphasis in the records continuum model is the participatory nature of the design phase whereby archivists or records managers and systems designers participate in the designing of the system and the involvement of both the archivists and records managers in the continuum of records keeping. The model is also based on the realization that records continue to live after the non-current phase of the records life-cycle. In support of the participatory approach, one could also argue that without the participation of archivists and records managers in the system design stage, records may disappear in the subsystems due to a lack of records management and archival knowledge on the part of corporate information systems designers. Furthermore, if records management professionals are not involved in the design phase, some records might not be captured in the system.

Important as it is, the records continuum theory must be used with caution. According to Upward (2000:116), 'for other practitioners and educators, however, its relevance is not immediately perceived. In face-to-face discussion with those who have been perplexed all I have ever been able to do is shrug my shoulders.' Shrugging shoulders may mean different things to different people. Perhaps, Upward's shrugging of shoulders may be indicative of his recognition of the nebulous nature of the records continuum theory.

Furthermore, Upward (2000) concedes that the records continuum framework is culturally oriented. In his own words: 'We fit our detailed knowledge into ways that are agreeable to our communities of practice. There is certainly a cultural component to Australian use of the word continuum' (Upward 2000:127). In that light, the continuum model should not be perceived as a paradigm shift in the management of records in the sense used by Kuhn (1962). Rather, it should be regarded as a cultural shift in the management of records driven by postmodernism. However, the model is important because it underscores the fact that records management activities are usually conducted in a certain cultural context to the extent that one size does not fit all. In that regard, records management cultures should strive to meet the needs of the environment in which records are generated and used.

As the records life-cycle, the continuum theory is concerned with managing records from creation to disposal from current systems either by destruction or long-term preservation in some form of archive. However, the major difference between the two theories is that the latter deconstructs the custodial mentality (in the postmodernist sense), which is perceived to be unattainable in the digital world, and further advocates the involvement of both records managers and archivists in the continuum of managing records.

\subsection{Hybrid records life-cycle theory}

We appreciate that both the continuum model and the records life-cycle theory have a lot to 
contribute to records management practices. In that regard, this study blended the prenatal stage of the records continuum with the records life-cycle conceptual stages in order to come up with the hybrid model that is suitable for managing records in the African business context as described below. In this context, the traditional records life-cycle was used as the backbone of the proposed hybrid conceptual model because studies have shown that the theory is popular in many countries in sub-Saharan Africa (SSA) (Ngulube and Tafor 2006).

It is evident from a participatory design viewpoint that the prenatal stage of the records continuum model is an important aspect in records management systems designs, therefore, the study blended the prenatal stage of the records continuum and all stages of records lifecycle theory as the foundation of the research. The blended theory that guided this study is called a modified records life-cycle theory or hybrid records life-cycle model.

The attributes of the hybrid model are as follows:

- Prenatal phase. In this stage a participatory design approach is considered. Records managers and archivist, management and other stakeholders participate in the records keeping system design.

- Current phase. Records creation or receipt, storage and maintenance for administrative use. Activities are the creation and capture of records and accessibility of records.

- Semi-current phase. In this phase records are rarely used, the phase involves on site or off site storage of records in records centres. The major activities are transferring records to the records centres or intermediate storage for efficient accessibility and space management purposes.

- Non-active phase. At this stage records have finished their active life and are not needed for immediate use in the current records systems. At this phase records are disposed of either by destruction or transfer to some archive depending on their enduring value.

\subsection{Linking the theoretical framework to the research problem}

The records management theories and principles described in the preceding text may be adapted to the management of business records. In fact, Bilotto and Guercio (2003:136) point out that archival and records management theories and principles are increasingly becoming relevant at a corporate level. In that regard, this study used the hybrid records life-cycle model to investigate the management of business records in nine exporting companies in the Iringa region of Tanzania. The research questions that guided the study were as follows:

- How much support does top management give to records management activities in the respective companies?

- Are there established policies for the management of records?

- How are electronic records managed?

- To what extent do companies comply with standards and regulatory frameworks?

- What are the highest educational levels and records management training of heads of records management systems?

- Do companies have vital records and disaster management programmes?

- What are the appraisal procedures and retention schedules for corporate records?

- How is access to corporate records managed?

\section{Methodology: a short research story}

The study used the survey method to investigate records management practices in nine exporting companies from the Iringa region in Tanzania. Asas Group of Companies, Brooke 
Bond Tanzanian Limited, Chai Bora, Dabaga Vegetable and Fruit Canning Company, Mufindi Tea Company, Sao Hill Saw Mill Company, Tanganyika Wattle Company and Kibena Tea Company, Tanzania Pyrethrum Processing and Marketing Company and Tanzathai IR Company comprised the units of analysis. The survey method was deemed to be appropriate because some researchers investigating existing records management practices in organizations used it with varying degrees of success (Chinyemba and Ngulube 2005; Kalumuna 2000; Ndibalema 2001; Ngulube and Tafor 2006).

A list of the target population was obtained from the business profile of the Iringa region at the Iringa Regional Trading Office. Access to the study population was made relatively easier by the fact that the first author obtained clearance to do the research from the Government of Tanzania. However, three out of the nine companies were initially uncooperative because they felt that the research was going to expose their confidential information and trade secrets. However, the problem was solved after the researcher had given them assurance that confidentiality was going to be respected, and that the results were going to be reported in aggregate with the collected data being used only for the purpose of the research.

Primary data were collected using interview protocols and observation schedules. Collection of data through the use of different methods was partly done to improve the validity of the research effort. The variables to be investigated were identified from the literature and the hybrid records model. The interview protocol was administered by the first author to heads of the records management systems in the nine exporting companies. In the case of observation the first author used the observation schedule and completed all the items under the predefined categories of variables to be observed. Data from interviews and observations were collated during analysis and reported in aggregate. Contradictions in the data were resolved during the process of analysis.

\section{Challenges to managing business records in Tanzania: presenting the findings]}

There are many challenges to managing business records. The authors identified from the literature and the hybrid records framework the following factors as the major challenges to managing business records in SSA in general, and Tanzania in particular:

- Policies for the management of records and management support for the records programme

- Managing electronic records

- Compliance and standards

- Staffing and professionalism

- Vital records protection programmes

- Disposition and retention of records

- Disaster management and control

- Managing access.

The following sections discuss these challenges in relation to the responses of the nine exporting companies that were surveyed between 2004 and 2005 in the Iringa region of Tanzania.

\subsection{Policies for the management of records and management support for the records programme}

The international standard for the development of records management programmes, ISO15489-2 Information and Documentation-Records Management-Part II, emphasizes the 
importance of records management policies and support for records management from senior management of an organization (International Standards Organization (ISO) 2001b). As part of the survey it was found that top management supported records management activities in six companies. Seven companies out of nine did not have a specific budget for corporate records management. Contrary to the perception of the respondents about management support of records management operations, the fact that there were no specific budget lines for records management activities show that records management activities were given a low priority.

The research also revealed that the majority of the companies did not have a records management committee. A study by Yusof and Chell (1999) bemoans the absence of records committees in many companies in Malaysia. However, records management committees are fundamental to designing records keeping systems and sharing information about appraisal decision making between various stakeholders. That tends to reduce conflict and suspicion among stakeholders about the perceived value of records and their ultimate disposal. Management in the surveyed companies has set future priorities in relation to records management issues in their organizations as detailed in Table 1. Management's 'wish' list demonstrates its commitment to improving records management activities in their companies.

Table 1 Management's future priorities in relation to corporate records management

\begin{tabular}{|l|c|}
\hline Future priorities for records management & Total \\
\hline Establishing records committees & 4 \\
\hline Addressing problems posed by computer-generated records & 5 \\
\hline Obtaining adequate training for records staff in the company & 5 \\
\hline Managing electronic records & 7 \\
\hline Conducting a records inventory & 6 \\
\hline Creating records retention schedule & 4 \\
\hline File management & 6 \\
\hline Needs assessment & 3 \\
\hline Managing archival records & 3 \\
\hline
\end{tabular}

Five respondents revealed that there was a formal records management policy in their companies and that the policy provided statements of company records management objectives. Two respondents indicated that their policies defined responsibilities for corporate records management, provided a company records management plan and guidelines for managing electronic records. One respondent specified that the policy provided guidelines for appraisal, schedules and disposition of records. On the other hand, four revealed that their companies did not have a records management policy. It is important for organizations to have formal policies to facilitate a creative allocation of funds and staff. Formal policies also serve as binding contracts between the organization and the stakeholders. They help set standards. Formal policies can also be used as tools for staff training and evaluation.

\subsection{Managing electronic records}

The business environment is rapidly changing due to the growing volumes of electronic information that is generated on a daily basis. Managing electronic records poses the greatest management challenge for records keepers. They face many impediments in trying to maintain authentic, reliable, usable and trustworthy records as envisaged in the ISO 15489 guidelines. 
There are legal, technological and organizational matters that records managers have to contend with to effectively manage electronic records. Technologically speaking, electronic records are machine readable, the storage medium is fragile and transient, and the longevity of the hardware and software is not guaranteed. Organizational matters in the management of electronic records include processes such as staffing, accessioning, indexing, retention scheduling and preservation of records and related policies. The legal side of managing electronic records may include providing evidence of the integrity of an electronic document through the use of metadata and managing records for compliance with laws.

Given the prevalent use of information technology in many businesses, it was important for this study to determine the incidence of computer usage by the companies under study. The study discovered that all nine companies used computers in various business activities. The uses of computers are summarized in Figure1.

Figure 1 Uses of computers in nine companies

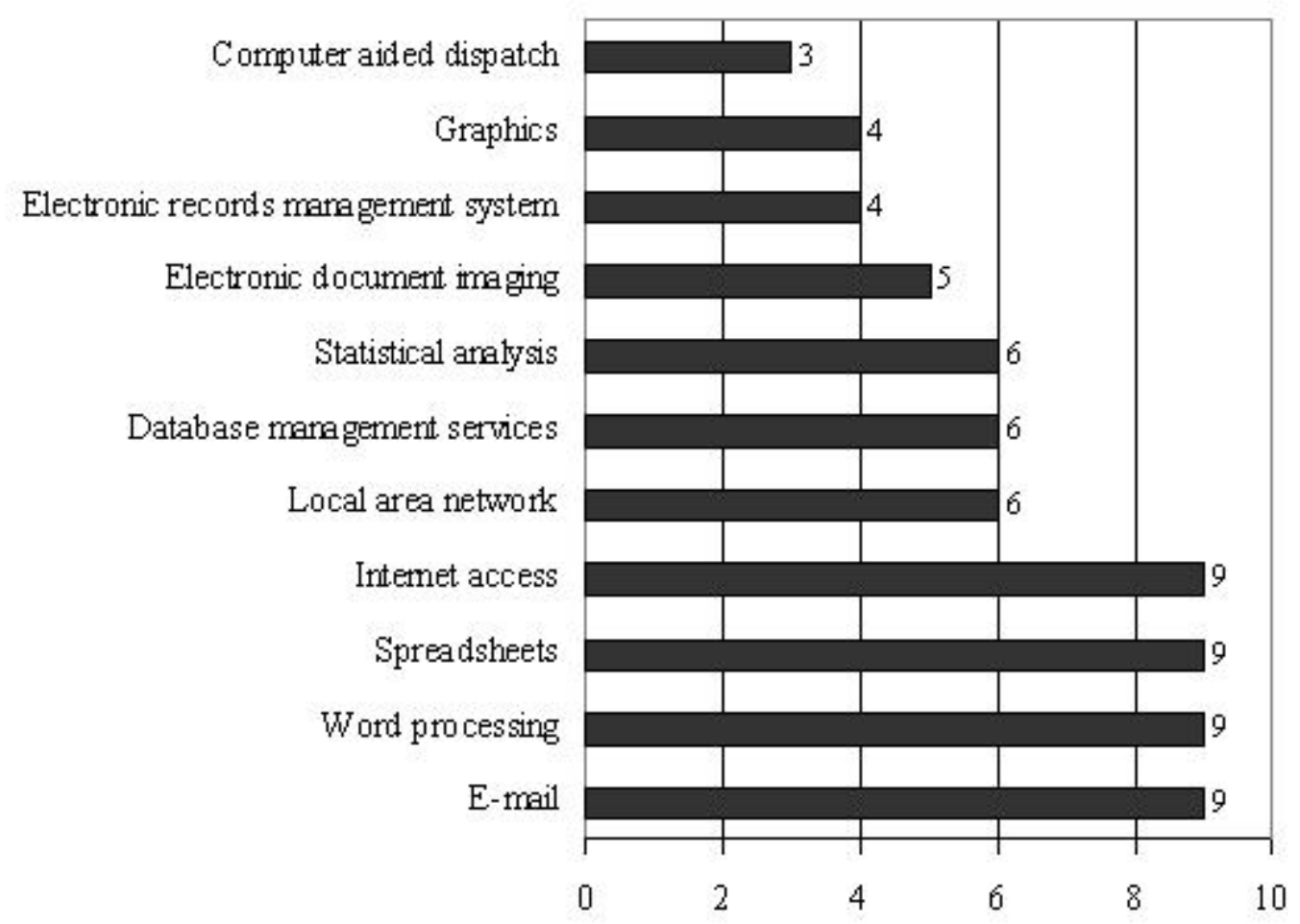

The results also revealed that only three companies had a Web site, but the Web sites were not managed as part of the records keeping systems. In other words, there were no processes for managing Web sites as records. Five companies indicated that they were using templates to create electronic records. Records management was not fully integrated with information technology in six companies. Only four companies registered the records that they had created or received. Eight companies did not create indexes for records created or received. Five companies had experienced the loss of electronic records mainly due to computer failures. Only three companies added metadata to their electronic records. Five companies said they had policies for migration of electronic records, while six had policies for the protection of records from alterations. However, companies neither had written procedures for records migration processes nor for records protection.

Studies have shown that electronic information is vulnerable because many organizations in SSA do not have adequate plans for migrating records to ensure continued access and authenticity in the face of changing hardware and software platforms (Ngulube 2004:37). In 
addition to formulating migration strategies, the surveyed businesses should also investigate the utility of preservation methods that have been suggested for digital data such as technology preservation, refreshing, emulation, data archaeology and output to analogue media.

It is evident from the results that the provision for the management of electronic records was unsatisfactory. Most of the companies had a fragmented approach to managing electronic records. Electronic records management was not done enterprise wide. As a result, the corporate memory of many companies was in danger of being lost in the bytes and computers. Records keepers should strive to keep the documentary heritage of their organizations secure and usable irrespective of format to foster accountability and transparency and protect the rights of all stakeholders. There should be end-to-end lifecycle management of electronic records to ensure that they are appraised, accessioned and preserved into the future. However, it was encouraging to discover that the future priority of seven companies was to manage their electronic records according to best practices.

Since all companies used e-mails, it was important to investigate how e-mails were captured in the records management systems. Information Management Professionals (ARMA) International identified e-mail management as one of the top-three records and information management challenges facing records keepers (Hermann 2005:26). Gartner Group research showed that approximately $75 \%$ of a firm's 'knowledge exchange' is via e-mail. Furthermore, the number of requests for organizations to produce e-mail for review has increased ever since the Enron scandal in the United States in 2001 (Johns 2005:12). Although e-mails are primary sources of evidence, many organizations do not manage them properly. For instance, the Reagan administration lost a lawsuit in the 1990s relating to the Iran-Contra Affair as result of missing e-mails. The problem of managing e-mails is compounded by the fact that existing e-mail systems have limited capacity to effectively manage messages that organizations may want to keep.

The results of the survey showed that seven companies printed e-mails to analogue media for future reference. Only one company classified e-mails electronically before saving them in an electronic medium. The question that arises is: Which record should be treated as the original when verifying authenticity, the printed version of the e-mail or the one that is kept in the electronic environment? The authors will leave the debate open to the reader.

Five companies had an e-mail policy. The lack of e-mail policies is not peculiar to the Iringa region. A study in USA revealed that many companies were largely unprepared to manage their e-mail due to the inadequacy of their policies and processes (Swartz 2005:6). In the light of numerous risks associated with loss of records, it is important to manage electronic mail as records and ensure that they are available as long as they are required.

\subsection{Compliance and standards}

Business records should be managed for them to comply with regulatory, legal and ethical requirements. Compliance is mainly concerned with information integrity, privacy and records retention (Marobella 2005:18). Put differently, compliance fosters accountability and good governance, especially in the private sector where business activities are not always open to public scrutiny. Compliance with legislation and standards has an impact on how records and information are captured or created, transmitted and used, stored, indexed, retrieved, controlled, retained and preserved.

Compliance can be mandatory or optional. For instance, compliance with ISO 9000 and ISO 15489 may be optional, but it is a mandatory requirement that organizations comply with laws and regulations. Regulatory compliance is becoming very popular for various reasons, but the major impetus behind it is to be found in the scandals and expensive lawsuits that 
have rocked the developed world and the need for certification with international standards. Furthermore, the globalization of markets and business is making compliance a major challenge for business organizations in SSA. The need to operate in international markets is persuading many companies to adhere to compliance requirements that govern the conduct of business in the countries with which they would be trading.

On the other hand, the need for certification of products and processes is compelling companies to adopt certain records management practices. In that regard, what comes to mind are the ISO 9000 and 14001 series and Eco-Management and Audit Scheme (EMAS) that require evidence from records to demonstrate the sustainable manner in which business activities would have been carried out. Multinational companies operating in Africa are also bringing compliance to the fore because of the need to align their procedures and processes with those of their partners at their headquarters overseas. It is evident that the compliance wave poses one of the major challenges to the management of business records in SSA.

As part of the survey, the respondents were asked if they were aware of the existence of compliance guidelines such as the ISO standards for quality assurance as well as environmental and records management. The results showed that seven were not aware of the existence of these standards and only two respondents were aware of these standards and their companies compliance with them. There is a need for records management personnel to familiarize themselves with standards that have an impact on how they manage recorded information, and how their records management activities have a bearing on the certification of their products and services on the international landscape. International companies are likely to trust doing business with business organizations whose activities are governed by standards and auditable business processes. It is evident that compliance with optional standards was not a top priority for most of the companies in the Iringa region. However, all their records management processes were compliant with regulations such as the tax and customs and excise laws.

\subsection{Staffing and professionalism}

The background information regarding the job title, education and training of heads of records management was important since it could explain the records management practices in the companies under study. The results showed that seven of nine exporting companies in the Iringa region used an administrative officer to head their records management systems processes. Two companies used 'information manager' as the job title for the head of records management. The findings also indicated that five companies used people with a degree and above to head the records management section while four companies used non-graduates. However, most of their qualifications were not directly related to records management. As far as the records management training was concerned, the results showed that three companies provided in-house training, one company trained staff at a records management college, another used paraprofessionally trained personnel and four companies did not train their heads of records management.

To manage records according to the records life-cycle, records continuum theory or the hybrid model adopted by this study, it is essential for records personnel to be properly trained. According to Yusof and Chell (1998:25) 'education and training are essential elements in the life long development of skills and expertise'. Ngulube (2001/2002:32) argues against holding records personnel accountable when they are not trained, 'since they would not have been empowered to do so'.

Preferably, records management training should be pursued in recognized training institutes or universities. The fact that heads of records management in the companies in this study attended records management training but did not deliver professional records management services in these companies demonstrate the fact that the training might have been 
inadequate because of the nature in which it was conducted.

\subsection{Vital records protection programmes}

Vital records provide legal status of the companies and could protect stakeholders' rights in the companies (Jaderstrom, Kruk and Miller 2002:265). Vital records could be all the records containing information about those with rights and having special interest in the organizations. Together with policies and procedures to guide the management of all records, companies need to have a special programme for vital records management. Owing to the importance of vital records in the operations of the companies, it was necessary to assess the treatment of these important records. The results also showed that only one company had an integrated written vital records programme. Four companies kept vital records separate on the same site. Four companies stored the duplicate copies of their vital records remotely at their head offices in different cities or countries. Companies that kept their records remotely at their head offices in other cities or countries kept their vital records more safely than the companies that kept them on site.

\subsection{Disposition and retention of records}

Records retention and disposition are fundamental to efficient and effective records management. In that regard, they should be the focal point of any records management function. They help the organization to:

- Control the growth of records

- Achieve compliance with records retention legislation

- Reduce financial liability and litigation risks that may result from missing information.

The survey revealed that seven companies closed their files regularly. However, the findings showed that only one company transferred inactive records to some kind of on-site archives. The results of observation revealed unprofessional treatment of inactive records in almost all companies except the one company with an on-site archive. Worse enough one company dumped inactive records in an attic. With regard to electronic inventories, the survey revealed that eight companies did not inventory their electronic records and seven companies did not conduct inventory of their paper-based records.

Table 2 Appraisal guidelines and disposal schedules

\begin{tabular}{|l|c|c|}
\hline Appraisal guidelines and disposal schedules & Yes & No \\
\hline Existence of guidelines for electronic records appraisal & 2 & 7 \\
\hline Existence of guidelines for paper-based records appraisal & 0 & 9 \\
\hline The company has a disposal schedule for electronic records & 1 & 8 \\
\hline The company has a disposal schedule for paper based records & 3 & 6 \\
\hline Retention schedules & 4 & 5 \\
\hline
\end{tabular}

Three companies appraised records at the end of the records life-cycle and six did it on an ad hoc basis. Six companies did not conduct appraisal of their records. Table 2 shows that retention scheduling was not satisfactory. Despite the benefits associated with records retention schedules most exporting business organizations in the Iringa region tended to overlook this aspect of records management. However, every company should have retention policies in order to 'determine how long it should keep certain records, including e-mail and Web pages. The [policies are] important for many reasons, including legal requirements that apply to some documents' (Gall 2000). However, six companies indicated that their future priority was to inventory their records irrespective of format and formulate retention schedules. 


\subsection{Disaster management and control}

Disaster planning is generally regarded as an essential part of any records management programme. Disaster planning ensures that institutions are prepared to respond quickly to emergencies. Disaster mitigation, or the ability to identify risks and prevent some emergencies from happening, should always play a key role in an institution's emergency preparedness and planning efforts. Despite the fact that a disaster preparedness plan allows an organization how to plan and make decisions about emergency response and recovery, most companies in the Iringa region had not made it part of their records management strategy.

One company had a disaster management plan. The results showed that only two out of nine companies had fire extinguishers in the records storage areas, one company had a sprinkler and none had fire detectors. It is evident that many records were not safeguarded against risks associated with fire. With regard to emergency telephone numbers, only one company had very clear and visible emergency telephone numbers for the police and internal fire section. Companies in the Iringa region should give serious thought to developing disaster management plans. Risk assessment and risk analysis should be the foundation of their disaster plans. The two processes would help them to identify, analyse and evaluate risks that are likely to affect them and the adequacy of the available controls to deal with the probable disasters.

\subsection{Managing access to business records}

The three common strategies used by organizations to maintain and use records are centralized, decentralized and a combination of the two (Ellis and Mauldin 2003; Shepherd and Yeo 2003:173). According to Ellis and Mauldin among the advantages of a centralized system are:

- Reduced complications in handling the system

- Reduction of infrastructure requirement

- Easy promotion of standardization

- Cost reduction

- Easy alignment of corporate objectives with the records system

- Simplified reporting and accuracy.

The advantages of decentralized systems are:

- Increased control at the local level

- Departmental specific needs are met easily

- Departmental cost management is easy

- Easy creation of local reports

- Improved control over resources.

Given the advantages and disadvantages of the centralized and decentralized systems, Ellis and Mauldin (2003) prefer a combination of centralized and decentralized systems in order to gain the advantages of both.

In the case of records control procedures and storage facilities, the study discovered that four companies used a combination of centralized and decentralized records control systems. Three companies used a decentralized and two used centralized systems. Perhaps there is need for companies in the Iringa region to consider the combination of the two systems so that they may benefit from the advantages that the systems offer. Even though Shepherd and Yeo (2003:173) argue for a choice of a system to be determined by the size of the organization and the availability of resources, they also point out that 'for many organizations, a mixture of centralized and decentralized storage is appropriate'. 
Furthermore, in the control procedures only four companies tracked their records using movement books. One company tracked by file movement book and one tracked records electronically. It is recommended that companies not using formal records tracking systems introduce a file tracking system for records safety and easy control of records movement. The companies are advised to use file movement books, cards, electronic or automated file tracking, using spreadsheet or database application software.

The findings for a filing system showed that the dominant filing system was functional, which was used by five companies. Two companies used numerical and alphanumerical systems. However, it was observed that companies used different systems in different sections or departments. Eight companies indicated that their filing systems effectively supported users' functions. Six companies had finding aids in place while only two had accessible findings aids. Five companies used secretaries to assist users to locate records. Only three companies managed to retrieve their information in less than five minutes. Six companies retrieved information within six to ten minutes.

\section{Concluding remarks}

It is clear that the exporting companies under study did not base their practices on any of the existing theories of records management. This study contends that companies in the Iringa region should embrace the hybrid records model suggested in this article as it strikes a balance between the records life-cycle model and the records continuum theory. The use of the suggested hybrid model may help companies to establish integrated policies that encompass the entire corporate information system. That will ensure that basic records management activities such as the design of compliant records systems, management of semi-current records and inactive records, establishment of records committees, appraisal and inventorying records would be prioritized.

In relation to the security of records, companies should establish disaster management plans and keep duplicate copies of vital records off site. Emergency telephone numbers for fire, disaster response and police should be made easily accessible. It is also recommended that the records management systems of the companies in this study be improved in order to retrieve recorded information in less than five minutes.

Since records were closed regularly in the companies, companies must establish semi-current records and inactive records programmes. Companies are advised to inventory their records and create appraisal guidelines. It is also recommended that companies establish retention schedules from the records inventory lists to indicate retention periods for individual records. Well-trained personnel should also manage business records. To that end universities and recognized institutes should be used for records management training.

Furthermore, companies must endeavour to comply with the ISO 15489 standard on records management best practices. Model Requirement for the management of electronic records (MoReq) could also be used in managing electronic records. MoReq is one of the comprehensive specifications of the functional requirement for the electronic records management. MoReq specifies classifications, records, documents, retention schedules and other related issues in both electronic and paper-based records (Cornwell Management Consultants 2004). To maintain the recordness of electronic records, it is recommended that metadata should be added to all electronic records created or received by the companies. Records management professionals should also provide leadership and guidance in the development of electronic records management policies to ensure that Web sites are managed as records. 
Finally, there is a need for research on other cases either in Tanzania or in any part of Africa to find out if this study can be replicated. In addition, studies on the feasibility of the use of the hybrid records theory in the management of business records should be undertaken. The information obtained from various research efforts may be used to build a database of information that, together with other cases, will confirm or refute the fact that the framework may be used to manage business records throughout their life-cycle. According to Rowley (2002:21), 'the more cases that can be marshalled to establish or refute a theory the more robust the research outcomes'.

\section{References}

Abbott, B.S. 2001. The state of electronic records management in South Africa: an overview. ESARBICA Journal: Journal of the Eastern and Southern Africa Regional Branch of the International Council on Archives 20:62-70.

Akussah, H. 1996. Records management: an overview. African Journal of Library, Archives and Information Science 6(2): 101-106.

An, X. 2001. A Chinese view of records continuum methodology and implications for managing electronic records. Paper presented at an international symposium on OA System and the Management of Archival Electronic Records: Theory and Practice, Hangzhou, China. [Online] Available WWW: http://www.caldeson.com/RIMOS/xanuum.html (Accessed 2 November 2004).

Bantin, P. 2002. Electronic records: a review of a decade and a reflection of future directions. In: Kent, A. and Hall, C.M. (eds). Encyclopedia of library and information science 74. New York: Marcell Dekker: 47-81.

Bilotto, A. and Guercio, M. 2003. The management of corporate records in Italy: traditional practice and methods and digital environment. Records Management Journal 13(3): 136146.

Chachage, B. 2005. Developing a model for a corporate records management system with special reference to sustainability reporting in Iringa region, Tanzania. PhD. thesis.

Pietermaritzburg: University of KwaZulu-Natal.

Charman, D. 1984. Records surveys and schedules: a RAMP study with guidelines. Paris: UNESCO.

Chinyemba, A. and Ngulube, P. 2005. Managing records at higher education institutions: a case study of the University of KwaZulu-Natal, Pietermaritzburg Campus. South African Journal of Information Management 7(1). [Online] Available WWW:

http://general.rau.ac.za/infosci/raujournal/default.asp?to=peervol7nr1 (Accessed 25 August 2005).

Cornwell Management Consultants. 2004. Model requirement for the management of electronic records. [Online] Available WWW: http://www.cornwell.co.uk/moreq (Accessed 25 August 2005).

Eastwood, T. 2006. Challenges old and new: managing archives in our times. ESARBICA Journal: Journal of the Eastern and Southern Africa Regional Branch of the International Council on Archives 25:2-15. 
Ellis, J. and Mauldin, T. 2003. Learning in the large enterprise: centralized vs. decentralized. [Online] Available WWW: http://www.clomedia.com/content/templates/ (Accessed 21 November 2004).

ESARBICA. 2005. XVIII Biennial ESARBICA General Conference on Archives and Records in the Information Society held in Gaborone, Botswana, July 2005.

Flynn, S. 2001. The records continuum model in the context and its implications for archival practices. Journal of the Society of Archivists 22(1):79-93.

Gall, B.W. 2000. Document retention policies: legal reasons to keep e-mail, Web pages and other records. [Online] Available WWW: http://www.gigalaw.com/articles/2000-all/gall2000-09-all.html (Accessed 15 December 2004).

Goodman, E.C. 1994. Records management as an information management discipline: a case study from SmithKline Beecham Pharmaceuticals. International Journal of Information Management 14(2):134-143.

Hardcastle, S. 1989. Providing storage facilities. In: Peter, E. (ed.) How to manage your records: a guide to effective practice. Cambridge: ICSA Publishing.

Hare, C.E. and McLeod, J. 1997. Developing a records management programme. London: Aslib.

Hermann, P.R. 2005. The top-three records and information management challenges. Office Solutions 22(2):26.

International Standards Organization (ISO). 2001a. ISO 5489-1: Information and Documentation - Records Management. Part 1: General. [Online] Available WWW: http://www.iso.ch

International Standards Organization (ISO). 2001b. ISO 15489-2: Information and Documentation - Records Management. Part 2: General. [Online] Available WWW: http://www.iso.ch (Accessed 15 December 2004).

Jaderstrom, S., Kruk, L. and Miller, J. 2002. Complete office handbook. New York: Random House Reference.

Johns, P. 2005. Learning the compliance lesson. AIIM E-Doc Magazine 19(3):12.

Kalumuna, G.F. 2000. Towards improving efficiency in records management in local authorities: the case of Dar Es Salaam Municipalities. M.A. Thesis. Dar Es Salaam: University of Dar Es Salaam.

Kennedy, J. and Schauder, C. 1999. Records management: a guide to corporate record keeping. 2nd ed. Melbourne: Wesley Longman.

Kitalu, R.S. 2001. Managing public records: the case of current records of the ministry of education and culture. M.A. Thesis. Dar Es Salaam: University of Dar Es Salaam.

Kuhn, T. 1962. The structure of scientific revolution. Chicago: University of Chicago Press.

Marobella, J.R. 2005. The world is watching: can US and Western European regulatory environment help predict future global initiatives? The Information Management Journal 39 (2):18-20. 
McKemmish, S., Reed, M. and Piggott, M. 2005. The archives. In: McKemmish, S., Piggott, M., Reed, B. and Upward, F. (eds). Archives: recordkeeping in society. Wagga Wagga:

Center for Information Studies: 159-195.

Mukangara, F.E. 2000. Information resource management for policy formulation, implementation and program decision-making in government ministries in Tanzania. Ph.D. Thesis. Pietermaritzburg: University of Natal.

Mwango, S.R. 2000. Bringing order out of disorder towards good government: the need for improved management of personnel records in Tanzania. M.A. Thesis. London: University College of London.

Myburgh, S. 2005. Records Management and archives: finding common ground. The Information Management Journal 39(2):24-29.

Ndibalema, T.K. 2001. The state of records management in the National Social Security Fund Headquarters. M.A. Thesis. Dar Es Salaam: University of Dar Es Salaam.

Ngulube, P. 2001/2002. Challenges to preservation of our archival heritage. S.A. Archives Journal 42:27-36.

Ngulube, P. 2004. Fostering accountability and justice: opportunities for records managers in changing societies. ESARBICA Journal: Journal of the Eastern and Southern Africa Regional Branch of the International Council on Archives 23:23-32.

Ngulube, P. and Tafor, V.F. 2006. An overview of the management of public records and archives in the member countries of the East and Southern Africa Regional Branch of the International Council on Archives (ESARBICA). Journal of the Society of Archivists 27 (1):58-83.

Nyirenda, H.D. 1993. The development of archives administration in Tanzania 1963-1993: problems and prospects. M.A. Thesis. London: University College of London.

Penn, I.A., Pennix, G. B. and Coulson, J. 1994. Records management handbook. 2nd ed. Vermont: Gower.

Rowley, J. 2002. Using case studies in research. Managing Research News 25(1):16-27.

Sekimang'a, D.A. 1992. National policy on information systems and services for Tanzania: formulation and strategy for implementation. M.Sc. Thesis. Addis Ababa: Addis Ababa University.

Senge, P. M. 1990. The fifth discipline: the art and practice of the learning organization. New York: Doubleday/Currency.

Shepherd, E. and Yeo, G. 2003. Managing records: a handbook of principles and practices. London: Facet Publishing.

Standards Association of Australia. 1996. AS 4390: Australian Standard - Records Management. [Online] Available WWW: https://www.standards.com.au/ (Accessed 12 January 2006).

Swartz, N. 2005. Workplace e-mail, IM survey reveals risks. The Information Management Journal 39(3):6. 
United Republic of Tanzania (URT). 2002. Records and Archives Management Act, 2002. Dar Es Salaam: Government Printer.

Upward, F. 2000. Modelling the continuum as paradigm shift in recordkeeping and archiving processes, and beyond - a personal reflection. Records Management Journal 10(3):15-139.

Upward, F. 2005. The records continuum. In: McKemmish, S., Piggott, M., Reed, B. and Upward, F. (eds). Archives: recordkeeping in society. Wagga Wagga: Center for Information Studies: 197-222.

Yusof, Z.M. and Chell, R.W. 1998. Records management education and training world wide: a general overview of the current situation. Records Management Journal 8(1):25-54.

Yusof, Z.M. and Chell, R.W. 1999. Managing business records in Malaysia: awareness and attitudes among business managers. Information Development 15(4):228-234.

\section{Disclaimer}

Articles published in SAJIM are the opinions of the authors and do not necessarily reflect the opinion of the Editor, Board, Publisher, Webmaster or the Rand Afrikaans University. The user hereby waives any claim he/she/they may have or acquire against the publisher, its suppliers, licensees and sub licensees and indemnifies all said persons from any claims, lawsuits, proceedings, costs, special, incidental, consequential or indirect damages, including damages for loss of profits, loss of business or downtime arising out of or relating to the user's use of the Website.

ISSN 1560-683X

Published by InterWord Communications for Department of Information and Knowledge Management, University of Johannesburg 